\title{
Literature Review on Elderly Charitable Donations
}

\author{
Xiangfei XU, Zonghua LI \\ University of Jinan, Jinan, Shandong, China
}

\begin{abstract}
Elderly charitable donation as a form of social participation, it has a positive effect on physical and mental health as well as social integration. So far, the research about the older people to participate in charitable donations is still rare at home. In this paper, through reviewing the existing theories and study about the charitable donations, provide useful experience for the development of china's elderly charitable donations.
\end{abstract}

KEYWORD: Active aging; Elderly participation; Charitable donation

Various studies on "active aging" have conducted since 1999 when the World Health Organization had raised the slogan of active aging. Under the background of increasingly serious aging, promoting social participation of older persons is an effective way to implement "active aging" and to strengthen the social integration, at the same time, it could also relieve stress that caused by aging problem to some extent. Elderly charitable donations as a form of the elderly to participate in social activity, not only reflect the "independence, participation, dignity, care and self-realization" principle but also promote the health of the elderly aging and active aging. Through reviewing the existing theories and study about the charitable donations, we can understand the current situation and the influence factors about it.

\section{THE CONCEPTION}

Foreign origin of the word "charity" can be traced back to ancient Greek mythology. In Greek mythology, charity was regarded as "love for humanity". To Roman period, Cicero's theory of charity advocating people generously, and think this behavior is "good for beneficiaries to the giver and without loss". In the middle ages, the church charity became the major form of charity. Along with the development of the Catholicism and Protestantism, the charity also further development. Until the

This paper is the initial achievement of National Social Science Fund Project "Research on the rural empty nesters' satisfaction of life". industrial society, the modern charity began forming, it refers to "individual voluntary for vulnerable groups and public welfare donations"[1]. From the perspective of modern management point of view, "charitable donation" attributable to the scope of activities of the third sector in addition to the government, for-profit agency; according to macroeconomic point of view, it can be attributed to the field of consumption and investment, its positioning as a "third distribution of society. "[2] Comprehensive the above point of view, "charitable donation" can be defined as: for humanitarian motivation, individual or organization will donate the ownership of the property to others[3]. It is obviously that the elderly charitable donation is a behavior that emphasized the elderly as the major body of donation.

\section{THE THEORETICAL AND REALISTIC SIGNIFICANCE OF ELDERLY CHARITABLE DONATION}

Elderly charitable donations as a form of elderly to participate in society plays an important role both in the theory and in reality.

The activity theory that emphasize the elderly could find the meaning of life in the process of participate in social activities and they can also find the value of itself, set up their own positive selfimage, enhance satisfaction[4]. According to the Role theory, the elderly should be looking for a new role to replace the loss of the role with the decline in motility old age. We can know from the theory of alienation, the elderly become more introverted as 
the growth of the age, as the result, the elderly so slowly from the previous social roles and activities .The reason of this phenomenon was not only caused by their aging problem, but also resulted from shortage of social opportunity. These theories shows that older people need to actively participate in social activities, but also need opportunities to participate in society. These are older theoretical significance of charitable donations.

The relevant study of some scholars shows that older people who actively participate in social activities could be healthier. Social activity not only can reduce depression and improve cognitive function, can also increase life satisfaction, promote mental health and lower mortality[5]. Meanwhile, charitable donation as a form of social activity also has important implications for the development of the society. Comprehensive scholars' views, we can know charitable donations as a form of the third allocation, which plays an important role in helping the vulnerable groups, narrowing the wealth gap, improving the social security system and thus promoting social stability. In addition, older people participate in volunteer activities will sublimated idea of social security, promote the forming of the active aging society and realization of mutual selfhelp in society; At the same time ,charity donation could promote the establishment of social capital, foster community relations network and build social trust and promote the development of related organizations[6].

Other scholars believe that the elderly participate in charitable activity has also played a huge role in alleviating social contradiction. For a long time, the elderly as vulnerable groups of society have received a lot of attention, so many people question the elderly occupied too much resource and feel unfair, as a result, led to discord between the generations. For this problem, some scholars have suggested the elderly actively participate in charity, do like this not only could improve their image but also promote intergenerational harmony[7].

\section{THE STATUS OF CHARITABLE DONATIONS}

According to the body of the charity involved in philanthropy can be divided into two categories: one is individual philanthropy participated by individual citizens and the other is organizational charity behavior participated by various organizations, institutions[8]. Number of charitable donations is increasing, but the structure and flow of donation are still unreasonable, The individual charitable donations in the role of charitable donations as important but low proportion, and the elderly individual charitable donations belong to individual charitable donations, so in this paper, we focuses on the study of individual charitable donations

\subsection{The research work of this charitable donations' main body}

On the research about individual charitable donations, there were some achievement as follow:

Zhao Hailin has emphatically carried on the analysis of individual charitable donations modes. And divide it into three kinds of schema types. The author will be summarized as the following table:

Table 1. Three kinds of donation mode

\begin{tabular}{|l|l|l|l|}
\hline & $\begin{array}{l}\text { Temporary } \\
\text { mode }\end{array}$ & $\begin{array}{l}\text { Contingency } \\
\text { mode }\end{array}$ & $\begin{array}{l}\text { Contractual } \\
\text { mode }\end{array}$ \\
\hline Voluntary & weak & moderate & strong \\
\hline Motivation & conformity & Emergency & Charitable \\
\hline $\begin{array}{l}\text { Donation } \\
\text { frequency }\end{array}$ & Infrequently & Infrequently & Frequently \\
\hline
\end{tabular}

And on this basis, Zhao puts forward should focus on the development of contractual mode[8]. There was also related research about the role of individual charitable donations. For example, Deng Guosheng through analyzing the present situation of our individual charitable donations, puts forward the development of the individual charitable donations have irreplaceable basic role in charity[10] The analysis of $\mathrm{Wu}$ Yan also confirmed the view of individual charity donation is important[11]. Recognizing the importance of individual charitable donation, some scholars use the quantitative research methods to calculate and analyze the number and flow of individual donation, according to the conclusion we know the flow of donations is irrational and some scholars suggested that should use tax policy to regulate the flow of donations[12]. Focus on the problem of the individual charitable donations is unreasonable, some scholars study it from the perspective of social transformation. Analysis done in this perspective, it is useful to propose measures that comply with Chinese actual situation[13]. From the perspective of economics, Hong Jiang, Zhang Lei through the analysis of relevant quantity model, put forward to effective measures that promoting individual charitable donations is tax reforming, and suggests that raised charitable donations to the second assignment level up[14]. Domestic research on individual charitable donations is focus on a particular population .One of the most typical is the survey of Deng Wei that questionnaire-based survey, supplemented by case interviews. This survey focus on the behavioral and cognitive aspects of charitable donations of Xiamen university students. The conclusion shows that in addition to economic factors, donation education and charitable donations mechanisms are also important factors affecting the donation 
behavior[15]. Tang Wenjie conducted the survey focus on small and medium entrepreneurs, through quantitative analysis of the data, obtained the conclusion that the relationship between charitable donations' behavior with its own private happiness is directly proportional[16]. Zhao Baoai through the analysis of the Social Participation of the University Retirement Teachers, found the participating the charitable activity had positive effect on themselves and society and he further pointed out that the path of choice to participate in charitable activities[7].

The achievement of studies about individual donations could provide an important reference to elderly charitable donation.

\subsection{The study on individual charitable donations' motives and influencing facts}

Zheng Fengtian proposed several motivations on the basis of the theory of individual donations provided by foreign scholars, including altruistic motivation, the "solar thermal" motivation (which is aimed at achieving their satisfaction), and " signal driven" motivation (in order to gain better popularity)[18]. Some scholars based on the survey in five cities drawn the subjective motivations from data in addition to the above motivation, such as costs and benefits, psychological benefits, value and efficacy[9].

Most of the research on the influence factors of personal charitable donations were divided into two aspects, namely the demography characteristics and socio-cultural system factors. The influence factors of charitable donations include individual or family income, the age of the donor, taxes and so on. On this basis, some scholar proposed other facts such as cultural background, religious beliefs, degree of understanding of charities and so on. In addition, recognition of the charity donations will also affect people's charitable behavior[17]. The above is the general factor that influence individual charitable donations, but taking into account the particularity of the elderly, the physical conditions, the degree of psychological and the family's supporting as well as older people's ability to get information also be an important influencing factors.

External factors include Social factors and cultural factors as well as regime and so on. From the actual situation of china, we know security system is not fully developed, the mechanisms of donations are inadequate and the credibility of charity is low, the reason above will influence donations. Meanwhile, absence of charitable education, Charitable atmosphere is not strong are also important reasons[13].

\section{REFLECTION AND INSPIRATION}

\subsection{The shortcomings of research}

Among the researches of existing charitable donations, which put the elderly as the main body was less, most of them put businesses, students, entrepreneurs as the main body.

In terms of the research methods, most based on quantitative research methods, the qualitative research methods less than quantitative research methods. As a result, the researches don't have indepth understanding of the view of the elderly to participate in charitable donations.

Meanwhile Most of the previous research on the elderly always regarded the elderly as the vulnerable groups and ignored the initiative and enthusiasm of the elderly. Even though in the studies of voluntary services focus on elderly, most scholars research volunteer motivations, influencing factors of charitable donations. The number of the researches about the Organizational processes which can encourage the elderly to take an active part in charitable donations is less. The researches of organizational process include how to strengthen the cooperation between Governments, organizations and individuals to make the elderly active in charitable giving activities; how to establish effective information platform and channels for the elderly to enable them to participate effectively.

\subsection{Inspiration}

In the study of the elderly, we should pay special attention to the particularity of the group, and pay attention to the factors which can distinguish it from other groups. Meanwhile, according to their unique properties we should using appropriate methods to investigate and analyze. Research on elderly charities should emphasize the status of the elderly, develop their autonomy and creativity, avoid the elderly to participate in the activity as passive recipients. In this process, changing the concept of community and the elderly is very important. So the elderly should have active and correct selfunderstanding, improve satisfaction through participating in social activities.

Secondly, reversing the discriminatory views of the whole society that the elderly is incomplete and weak. Advocating the recognition of their abilities on the basis the "Respect the old, love the old" concept. Thirdly, the channel which the elderly to participate in social activities was not smooth, so we should take it as the priority study issue. Building an open platform for the elderly, to make them not only interested in charitable donations but can also actively involve.

Finally, while learning the mode of participating or related methods from other countries and regions, the research should in conjunction with 
their own cultural background factors, social environment and systems, taking into account the specific context of the transition period, from different disciplines and perspectives to develop a reasonable policy, system, and actively mobilize the enthusiasm of the elderly, providing all practicable protection for their participation in charitable donations .

\section{REFERENCES}

[1] Shi, J.Y. 2012. The origin, development and characteristics of modern philanthropy. Thinking(3).

[2] Wang, C.J. 2006. Empirically investigate the third assignment in charitable donations. Journal of Hefei University of Technology(5).

[3] Wang, C.J 2005.the research of Charitable donation in Public Administration Perspective. Journal of Shantou University (6).

[4] David • L •D. 1986. Elderly Sociology. Tianjin, Tianjin People's Publishing House.

[5] Pan.L \& Zeng, H \&, Li,T.T \&, Zhu,H.R \&, Lu ,X.F.2014. The research developement of elderly volunteers. New Progress.

[6] Wang, X.W \&, Duan, S.J. 2012.Triple realm of older people to participate in volunteer activities - Approaches based on active aging Discussion. Forward Position(1).

[7] Zhao, B.A. 2008. College teachers' retirement community participation - charity Perspective. Journal of Shandong Education Institute(4)
[8] Zhao,H.L.2010.Models of individual charitable donations. Economy and Society(2).

[9] Su, Y.Y. \& Shi, G.L. 2014. Charitable donations residents Factors - Based on analysis of the survey of the five cities. Social Science Research(3).

[10]Deng, G.S. 2007. Individual donation is the cornerstone of the development of philanthropy. Journal of zhongzhou(1).

[11]Wu, Y. 2008.Paying Attention to Personal Donations, Promoting Sustainable Development of Charitable Cause. Jounal of Xi'an university of finance and economic(1).

[12]Zhang, W.C. An Empirical Study on Contemporary Donation Management and Its Problems in China. With dynamic soft science research achievements.

[13]Yan, Y.L. \& Liu, X.L 2007.Social transition of our country civil charity status quo analysis. xuehui(10).

[14]Hong, L \& Zhang, J.2008. Economic Analysis of private charitable donations. Journal of Shanghai Economic Management College(3).

[15]Deng, W. 2008.Cognitive investigation of College Students charitable giving behavior. Journal of China Youth College for Political Sciences(5).

[16]Tang, W.J. 2013.Private entrepreneurs charitable giving behavior and subjective well-being. Social Sciences of ZheJiang(8).

[17]Zhao, Y.L. 2008. The analysis of Chinese charitable donations and the Related Factors. HLJ Foreign Economic Relations \& Trade(2).

[18]Zheng, F.T. \& Jiang, J.Q. 2009.Social mobilization mechanism of public goods. Social Sciences of Zhejiang(10). 